\title{
Liquid-based cytology for the detection of cervical intraepithelial lesions in Jimma town, Ethiopia
}

Getnet Tesfaw ${ }^{1 *} \mathbb{D}$, Yesuf Ahmed², Lealem Gedefaw ${ }^{1}$, Lamessa Dube³ ${ }^{3}$ Samson Godu², Kirubel Eshetu4, Mesfin Nigussie ${ }^{4}$, Haftamu Hailekiros ${ }^{5}$, Moses Joloba $^{6}$, Gelila Goba $^{7}$ and Alemseged Abdissa ${ }^{1}$

\begin{abstract}
Background: Cervical cancer is the second leading type of female cancer in Ethiopia. Screening for cervical cancer is primarily conducted using visual inspection with $5 \%$ acetic acid (VIA). Liquid-based cytology (LBC) is not yet widely used in Ethiopia.

Method: Women aged 21-65 years were tested using LBC and VIA to detect cervical dysplasia. Logistic regression analysis was conducted to identify associated factors. Cohen's Kappa test was conducted to test agreement between LBC and VIA.

Results: Forty-two percent $(n=188)$ of 448 participants were 31 to 40 years of age and only two participants were above 60. Of the 448 participants, 419 (93.5\%) were tested with LBC, 294 (65.6\%) VIA and 272 (60.7\%) with both LBC and VIA. Among women screened using LBC, 305 (72.8\%) were negative for intraepithelial lesion or malignancy (NILM), 97 (23.2\%) had low-grade squamous intraepithelial lesion (LSIL) and 17 (4.1\%) had high-grade squamous intraepithelial lesion (HSIL). Presence of cervical lesions was generally lower in younger and older women. Majority, $39(40 \%)$ of women with LSIL and 10 (59\%) with HSIL were 41-50 years of age. Women aged 51-60 were more likely to have abnormal intraepithelial lesions compared to women aged 21-30 (AOR $=20.9,95 \% \mathrm{Cl}=[7.2-60.9], p=$ 0.00). Out of 47 (10.8\%) HIV-positive women, 14 (32.56\%) had intraepithelial lesions of which 10 (23.3\%) and 4 (9.3\%) had LSIL and HSIL, respectively. Among women screened with VIA, 18 (6.1\%) were positive; among the 272 (60.7\%) women screened using both $L B C$ and VIA, 6 (2.2\%) were positive on both $L B C$ and VIA tests. The level of agreement between the two tests was weak at a statistically significant level (kappa value $=0.155, p=0.006$ ).

Conclusion: LBC demonstrated high rates of cervical squamous intra-epithelial lesions in our study. VIA was a less reliable predictor of cervical squamous intra-epithelial lesions than LBC. Evaluating diagnostic accuracy of both LBC and VIA against a histological endpoint should be completed before adopting either or both screening modalities.
\end{abstract}

Keywords: Liquid-based cytology, LBC, VIA, Cervical squamous intra-epithelial lesions, Ethiopia

\footnotetext{
* Correspondence: gettesfaw2@gmail.com

'Jimma University, School of Medical Laboratory Sciences, PO Box =378, Jimma, Ethiopia

Full list of author information is available at the end of the article
}

(c) The Author(s). 2020 Open Access This article is licensed under a Creative Commons Attribution 4.0 International License, which permits use, sharing, adaptation, distribution and reproduction in any medium or format, as long as you give appropriate credit to the original author(s) and the source, provide a link to the Creative Commons licence, and indicate if changes were made. The images or other third party material in this article are included in the article's Creative Commons. licence, unless indicated otherwise in a credit line to the material. If material is not included in the article's Creative Commons licence and your intended use is not permitted by statutory regulation or exceeds the permitted use, you will need to obtain permission directly from the copyright holder. To view a copy of this licence, visit http://creativecommons.org/licenses/by/4.0/. The Creative Commons Public Domain Dedication waiver (http://creativecommons.org/publicdomain/zero/1.0/) applies to the data made available in this article, unless otherwise stated in a credit line to the data. 


\section{Background}

Human papilloma virus (HPV) is the most common sexually transmitted infection (STI) in the world [1]. HPV causes a variety of malignancies, with cervical cancer being the most important and prevalent [2]. Cervical cancer is a leading public health challenge globally, with 569, 847 women were diagnosed and 311,365 women dying from the disease in 2018 [3]. Majority (85\%) of deaths occurred in low- and middle-income countries [4]. In Africa, 119, 284 new cases of cervical cancer were diagnosed and 81, 687 women died in 2018. The highest rate of cervical cancer was found in eastern and western region of Africa [3].

In Ethiopia, $5.8 \%$ of national mortality is attributable to cancer and incidence is increasing because of the aging population. Cervical cancer is the second leading cause of female cancer in women aged 15 to 44 in Ethiopia [5]. According to the Global Cancer Observatory, 6294 new cases were diagnosed and 4884 women died from the disease in 2018 [6]. According to the Ethiopian Ministry of Health, approximately $80 \%$ of reported cases of cancer are diagnosed at advanced stages [5].

In 2016, Ethiopia introduced a national cancer control plan that includes using visual inspection with acetic acid (VIA) and corresponding treatment of women testing positive. VIA continues to be the only cervical cancer screening modality in the country [5]. There is no organized cytology-based cervical lesion screening program in Ethiopia. As per the researchers' knowledge, no cervical cancer screening has ever been conducted in Ethiopia that combines LBC and VIA. This study documents the burden of cervical lesions and predictors of abnormal cervical cytology as well as comparing LBC and VIA screening modalities.

\section{Methods}

\section{Study design and setting}

A cross sectional study was conducted in Jimma Town from February 2017 to May 2018. Jimma is located 350 $\mathrm{km}$ southwest of Addis Ababa. A total of 448 nonpregnant women ages 21-65 who visited Jimma University Hospital as well as Marie Stopes International and Family Guidance Association of Ethiopia (FGAE) Clinics for VIA screening as part of the national cervical cancer screening program were enrolled consecutively. Women with complete hysterectomy, gross tumor on the cervix, prior surgeries involving the cervix, those who were menstruating, and those with no history of sexual activity were excluded. Written informed consent was obtained and the procedure of the test was explained to women.

\section{Demographic and risk factors}

Demographic information and risk factors for cervical cancer were collected using questionnaires prepared in Afan Oromo and Amharic languages. The collected data included occupation, educational status, age, parity, marital status, history of contraceptive use, age at first sexual intercourse, smoking habit, number of lifetime sexual partners, family history of cervical cancer, STIs and alcohol consumption.

\section{Liquid-based cytology (LBC)}

An automated liquid-based cytology, SurePath ${ }^{\mathrm{Tm}}$ liquidbased Pap test (BD, USA), was employed for cytological sample preparation. After removing obscuring mucus from the cervix with a cotton swab, endocervical and ectocervical cells were collected with cytobrush. This cytobrush was immediately rinsed in a vial containing SurePath Preservative Fluid. Samples were transported at room temperature for analysis at the International Clinical Laboratories (ICL) in Addis Ababa using BD PrepMate ${ }^{\text {TM }}$ and PrepStain ${ }^{\mathrm{TM}}$ Slide Processor. Vials containing samples were labeled and placed into the BD PrepMate ${ }^{\mathrm{Tm}}$ Slide Processor in which a liquid-based filtration process removed mucus and debris, preserving cell morphology, and making a smear of even distribution. All slides were stained with the BD SurePath Kit Cytology Stain and examined by two pathologists [7] who were enrolled in the College of American Pathologists (CAP) proficiency program and received stained LBC slides every three months as well as participating in the external quality assurance scheme. LBC test results were recorded based on the Bethesda gynecologic cytology guideline [8].

\section{Visual inspection with acetic acid (VIA)}

Women visited health facilities in Jimma Town involved in national cervical cancer screening program were enrolled for VIA. Women with invisible transformation zone were excluded from the study. After obtaining informed consent, a sterile plastic spatula was inserted into the vagina to visualize the cervix. Then, $5 \%$ acetic acid was applied to the cervix for one minute. Positive test was defined as a "sharp, distinct, well-defined, dense (opaque, dull or oyster white) aceto-white area with or without raised margins" according to the standard guideline $[9,10]$. VIA examination was done by experienced clinical nurses who participated in the national cervical cancer screening program using VIA.

\section{Data analysis}

Data was checked for completeness, coded and entered into EpiData v3.1 and exported to Stata ${ }^{14}$ for analysis. Descriptive statistics, frequency and proportion were used to describe demographic variables. Sub-group analysis was conducted for HIV patients. Logistic regression analysis was used to identify risk factors for abnormal cervical cytology on the LBC test. Cohen's Kappa test was used to assess agreement between LBC and VIA test ( $p$-value $<0.05$ was considered statistically significant at 95\% confidence). 
Table 1 Abnormal intraepithelial lesions by LBC and demographic characteristic, Jimma, 2018

\begin{tabular}{|c|c|c|c|c|c|}
\hline \multirow[t]{3}{*}{ Characteristics } & & \multirow[t]{3}{*}{ N (\%) } & \multicolumn{3}{|c|}{ Liquid-based cytology (LBC) Result } \\
\hline & & & \multirow{2}{*}{$\begin{array}{l}\text { NILM } \\
\mathrm{n}(\%)\end{array}$} & \multirow{2}{*}{$\begin{array}{l}\text { LSIL } \\
\mathrm{n}(\%)\end{array}$} & \multirow{2}{*}{$\begin{array}{l}\text { HSIL } \\
n(\%)\end{array}$} \\
\hline & & & & & \\
\hline \multirow[t]{5}{*}{ Age } & $21-30$ & $105(25.06)$ & $97(92.38)$ & $8(7.62)$ & $0(0.00)$ \\
\hline & $31-40$ & $179(42.72)$ & $144(80.45)$ & $30(16.76)$ & $5(2.79)$ \\
\hline & $41-50$ & $102(24.34)$ & $53(51.96)$ & $39(38.24)$ & $10(9.80)$ \\
\hline & $51-60$ & $31(7.40)$ & $11(35.48)$ & $18(58.06)$ & $2(6.45)$ \\
\hline & $>=61$ & $2(0.48)$ & $0(0.00)$ & $2(100.00)$ & $0(0.00)$ \\
\hline \multirow[t]{5}{*}{ Occupation } & Government worker & $159(38.8)$ & $100(62.89)$ & $46(28.93)$ & $13(8.18)$ \\
\hline & Merchant & $30(7.3)$ & $25(83.33)$ & $4(13.33)$ & $1(3.33)$ \\
\hline & Student & $11(2.7)$ & $10(90.91)$ & $1(9.09)$ & $0(0.0)$ \\
\hline & Housewife & $164(40.1)$ & $127(77.44)$ & $34(20.73)$ & $3(1.83)$ \\
\hline & Other & $45(11)$ & $36(80.00$ & $9(20.00)$ & $0(0.00)$ \\
\hline \multirow[t]{4}{*}{ Educational Status } & Illiterate & $84(20.14)$ & $57(67.86)$ & $26(30.95)$ & $1(1.19)$ \\
\hline & Primary & $110(26.38)$ & 91 (82.73) & $15(13.64)$ & $4(3.64)$ \\
\hline & Secondary & $91(21.82)$ & $66(72.53)$ & $23(25.27)$ & $2(2.20)$ \\
\hline & University & $132(31.65)$ & $90(68.18)$ & $32(24.24)$ & $10(7.58)$ \\
\hline \multirow[t]{4}{*}{ Marital Status } & Married & $313(74.88)$ & $240(76.68)$ & $62(19.81)$ & $11(3.51)$ \\
\hline & Single & $23(5.50)$ & $20(86.96)$ & $3(13.04)$ & $0(0.00)$ \\
\hline & Divorced & $28(6.70)$ & $22(78.57)$ & $5(17.86)$ & $1(3.57)$ \\
\hline & Other & $54(12.92$ & $23(42.59)$ & $26(48.15)$ & $5(9.26)$ \\
\hline \multirow[t]{3}{*}{ Parity } & Nulligravida & $34(8.17)$ & $29(85.29)$ & $3(8.82)$ & $2(5.88)$ \\
\hline & Primigravida & $70(16.83)$ & $55(78.57)$ & $13(18.57)$ & $2(2.86)$ \\
\hline & Multigravida & $312(75.00)$ & 219 (70.19) & $80(25.64)$ & $13(4.17)$ \\
\hline \multirow[t]{3}{*}{ Menstrual Bleeding Pattern } & Irregular & $151(37.1)$ & $131(86.75)$ & $18(11.92)$ & $2(1.32)$ \\
\hline & Regular & $120(29.48)$ & $111(92.50)$ & $9(7.50)$ & $0(0.00)$ \\
\hline & Menopause & $136(33.42)$ & $53(38.97)$ & $68(50.00)$ & $15(11.03)$ \\
\hline \multirow[t]{2}{*}{ Postcoital bleeding } & No & 377 (93.32) & 268 (71.09) & $92(24.40)$ & $17(4.51)$ \\
\hline & Yes & $27(6.68)$ & $24(88.89)$ & $3(11.11)$ & $0(0.00)$ \\
\hline \multirow[t]{2}{*}{ Age of first sexual intercourse } & $10-17$ & $183(44.74)$ & $132(72.13)$ & $45(24.59)$ & $6(3.28)$ \\
\hline & $>=18$ & $226(55.26)$ & $166(73.45)$ & $49(21.68)$ & $11(4.87)$ \\
\hline \multirow[t]{2}{*}{ Use of contraceptive } & No & $305(73.14)$ & $203(66.56)$ & $87(28.52)$ & $15(4.92)$ \\
\hline & Yes & $112(26.86)$ & $100(89.29)$ & $10(8.93)$ & $2(1.79)$ \\
\hline \multirow[t]{2}{*}{ Current sexual partner } & No & $138(33.17)$ & $87(63.04)$ & $43(31.16)$ & $8(5.80)$ \\
\hline & Yes & $278(66.83)$ & $216(77.700$ & $53(19.06)$ & $9(3.24)$ \\
\hline \multirow[t]{2}{*}{ Condom use during sexual intercourse } & No & $392(94.23)$ & $282(71.94)$ & $95(24.23)$ & $15(3.83)$ \\
\hline & Yes & $24(5.77)$ & $21(87.50)$ & $1(4.17)$ & $2(8.33)$ \\
\hline \multirow[t]{2}{*}{ Alcohol use } & No & $384(93.20)$ & $276(71.88)$ & $91(23.70)$ & $17(4.43)$ \\
\hline & Yes & $28(6.80)$ & $24(85.71)$ & $4(14.29)$ & $0(0)$ \\
\hline \multirow[t]{2}{*}{ Smoking } & No & 417 (99.52) & $303(72.66)$ & $97(23.26)$ & $17(4.08)$ \\
\hline & Yes & $2(0.48)$ & $2(100)$ & $0(0.00)$ & $0(0.00)$ \\
\hline \multirow[t]{2}{*}{ Chronic corticosteroid use } & No & $396(96.82)$ & $292(73.74)$ & $87(21.97)$ & $17(4.29$ \\
\hline & Yes & $13(3.18)$ & $6(46.15)$ & $7(53.85)$ & $0(0.00)$ \\
\hline \multirow[t]{2}{*}{ Number of lifetime sexual partners } & 1 & $247(61.75)$ & $174(70.45)$ & $63(25.51)$ & $10(4.05)$ \\
\hline & $>=2$ & $153(38.25)$ & $116(75.82)$ & $30(19.610$ & $7(4.58)$ \\
\hline
\end{tabular}


Table 1 Abnormal intraepithelial lesions by LBC and demographic characteristic, Jimma, 2018 (Continued)

\begin{tabular}{|c|c|c|c|c|c|}
\hline \multirow[t]{3}{*}{ Characteristics } & & \multirow[t]{3}{*}{$N(\%)$} & \multicolumn{3}{|c|}{ Liquid-based cytology (LBC) Result } \\
\hline & & & NILM & LSIL & HSIL \\
\hline & & & $n(\%)$ & $n(\%)$ & $n(\%)$ \\
\hline \multirow[t]{2}{*}{ History of sexually transmitted diseases } & No & $339(82.48)$ & $246(72.57)$ & $80(23.60)$ & $13(3.83)$ \\
\hline & Yes & $72(17.52)$ & $53(73.61)$ & $16(22.22)$ & $3(4.17)$ \\
\hline \multirow[t]{3}{*}{ HIV status } & Non-reactive & 135 (33.09) & $104(77.04)$ & $26(19.26)$ & $5(3.70)$ \\
\hline & Reactive & $43(10.54)$ & $29(67.44)$ & $10(23.26)$ & $4(9.30)$ \\
\hline & Unknown & $230(56.37)$ & $163(70.87)$ & $59(25.65)$ & $8(3.48)$ \\
\hline \multirow[t]{2}{*}{ Family history of cancer } & No & $350(94.85)$ & $254(72.57)$ & $80(22.86)$ & $16(4.57)$ \\
\hline & Yes & $19(5.15)$ & $14(73.68)$ & $5(26.32)$ & $0(0.00)$ \\
\hline \multirow[t]{2}{*}{ Pelvic examination } & Abnormal & $7(1.78)$ & $5(71.43)$ & $1(14.29)$ & $1(14.29)$ \\
\hline & Normal & 386 (98.22) & $284(73.58)$ & 86 (22.28) & $16(4.15)$ \\
\hline \multirow[t]{2}{*}{ SCJ visible } & No & $120(33.06)$ & $60(50.00)$ & 47 (39.17) & 13 (10.83) \\
\hline & Yes & $243(66.94)$ & 207 (85.19) & $32(13.17)$ & $4(1.65)$ \\
\hline
\end{tabular}

\section{Results}

\section{Characteristics of study participants}

Mean age of participants was $38(\mathrm{SD}= \pm 9)$ and ranged from 21 to 65 . Forty-two percent $(n=188)$ of women fell between 31 and 40 years of age. Only two participants were above 60 years of age. Three hundred thirty-three (74.3\%) women were married. One hundred ninety-four (44.5\%) had sexual debut between the ages of 10 and 17. Thirty-nine (8.8\%) were primigravida and 339 (74.1\%) multigravida and $163(38.3 \%)$ had two or more lifetime partners. Seventy-eight (17.7\%) had history of STIs and 47 (10.8\%) were HIV patients on ART follow-up at Jimma University's TB-HIV clinic [Table 1].

\section{Intraepithelial lesions screening by LBC and VIA}

Of 448 participating women, 28 (6.3\%) were missing LBC results and $1(0.22 \%)$ had an inadequate sample. The remaining 419 (93.5\%) women had LBC results, 294 (65.6\%) had VIA results and 272 (60.7\%) had both LBC and VIA results.

Among women screened using LBC, 305 (72.8\%) tested negative for intraepithelial lesion or malignancy (NILM), 97 (23.2\%) had LSIL and 17 (4.1\%) had HSIL. No ASCUS, ASC-H or squamous carcinoma was present. Cervical lesions consisting of either LSIL or HSIL were present in 114 (27.2\%) women. Presence of cervical lesions was generally lower in younger and older women compared to middle-aged women. Among women with cervical lesions, $8(7 \%)$ were below the age of 31 and $2(1.8 \%)$ were over 60 . Of the remaining women, $70(30.7 \%)$ were $31-40,49$ (43\%) were $41-50$, and $20(17.5 \%)$ were $51-60$ years of age. Thirty-nine (40\%) women with LSIL and 10 (59\%) with HSIL were between 41 and 50 years of age. Among the 419 women tested using LBC, 120 (33.1\%) had invisible SCJ during examination. Of these, 60 (50\%) had either LSIL or HSIL [Table 1].

Two hundred seventy-two (60.7\%) women were screened using both LBC and VIA. Among women screened using VIA, 18 (6.1\%) tested positive. Eleven (4.7\%) of these were among the $236(86.8 \%)$ cases recorded as NILM by using LBC. Of the 36 (12.1\%) women who had either LSIL or HSIL on the LBC test, 30 (83.3\%) tested negative on the VIA test. No women with HSIL tested positive using VIA. There was no agreement between the two screening tests using Cohen's Kappa test (kappa value $=0.155, p=0.006)$ [Table 2]

\section{Characteristics of HIV patients}

A total of $47 \mathrm{HIV}$ patients on ART who visited Jimma University Cervical Cancer Clinic were screened for cervical lesions. Of these, 21 (45.7\%) were married, 15 (31.9\%) were primigravida and 28 (59.6\%) multigravida and $23(48.9 \%)$ had sexual debut between the ages of 11 and 17. Thirty-two (68.1\%) had multiple sexual partners and 15 (32\%) had history of STIs.

Twenty-eight (59.6\%) and 43 (91.5\%) HIV-positive women were tested with VIA and $\mathrm{LBC}$, respectively. Only two HIV-patients were positive on the VIA test (7.1\%) whereas 14 (32.6\%) had either LSIL or HSIL on

Table 2 Cervical lesion abnormality among women screened by both LBC and VIA, Jimma, 2018

\begin{tabular}{llllll}
\hline LBC Result & \multicolumn{2}{l}{ VIA Test Result } & Total & Kappa value & P-value \\
\cline { 2 - 3 } & $\begin{array}{l}\text { Negative } \\
n(\%)\end{array}$ & $\begin{array}{l}\text { Positive } \\
n(\%)\end{array}$ & & 0.155 & 0.006 \\
NILM & $225(95.34)$ & $11(4.66)$ & $236(100)$ & & \\
LSIL or HSIL & $30(83.33)$ & $6(16.67)$ & $36(100)$ & & \\
\hline Total & $255(93.75)$ & $17(6.25)$ & $272(100)$ & & \\
\hline
\end{tabular}


the LBC test. Of this latter group, $10(23.3 \%)$ and 4 (9.3\%) had LSIL and HSIL, respectively. Among HIVpositive women between the ages of 41-50, 7 (77.78\%) had intraepithelial lesions. Half of HIV-patients with interepithelial lesions were between the ages of 41-50.

\section{Predictors of abnormal cytology by LBC}

Bivariate logistic regression analysis revealed that parity, age and condom use during sexual intercourse were significant for inclusion in the multivariate regression analysis at $\mathrm{p}=<$ 0.25 . Multivariate regression revealed that age was an independent predictor of LSIL and HSIL. Odds of being positive for cervical squamous-extraepithelial lesions were higher in women older than 31 years of age. Women 51-60 years of age were more likely to have abnormal intraepithelial lesion compared to women aged $21-30(\mathrm{AOR}=20.9,95 \% \mathrm{CI}=$ [7.2-60.9], $p=0.00)$ [Table 3].

\section{Discussion}

In Ethiopia, 29 million women are over 14 years of age and many of these women are at risk of developing cervical cancer [5]. In 2018, 6294 women were diagnosed as new cervical cancer cases and 4884 women died from the disease [6].

Even though cervical cancer burden is high in Ethiopia, the national cancer screening program is based solely on VIA, which has high variability due to examiners' judgment [11]. Our study is the first to show results of cervical cancer screening in Ethiopia using LBC. In our study, abnormal squamous intraepithelial lesion was present in 114 (27\%) women, which is higher than the $17 \%$ of women that were positive in a study in China [12]. Prevalence of LSIL and HSIL were $23.2 \%$ and $4.1 \%$, respectively, in our study, much higher than the $1.9 \%$ and $0.6 \%$ prevalence, respectively, observed in Sao Paulo [13]. A study in India reported a lower rate of LSIL (7.5\%) than our study, but higher HSIL (10.5\%) [14]. Significantly, lower prevalence of LSIL and HSIL (2\%) and (2.4\%) were observed in the
Netherlands and Germany, respectively, [15, 16]. Low rates in developed countries may be due to the availability of the HPV vaccines [17] and the presence of organized cervical cancer screening [18], which is new to Ethiopia.

In our study, a higher proportion of women aged 4150 tested positive on the LBC screening test. In contrast, we observed lower prevalence of cervical lesions in younger and older women. Visibility of SCJ is the prerequisite for VIA examination and women with invisible SCJ are exempt for VIA examination [19]. In our study, women with invisible SCJ, underwent LBC testing and $60(50 \%)$ had either HSIL or LSIL on the LBC test.

Logistic regression showed women aged 51-60 had higher odds of having cervical squamous intraepithelial lesions compared to younger women. LBC screening was better at detecting HSIL and cervical lesions in older women, which is not true for VIA screening [20].

HIV infection is a risk factor for persistent HPVinfection, a necessary condition for the development of squamous interepithelial lesions. HIV-positive women are disproportionately affected by cervical lesions [21]. In our study, 14 (32. 6\%) HIV-patients had cervical squamous intraepithelial lesions, which is higher than prevalence in the total study population (27\%). While the rate of LSIL (23.3\%) among HIV-positive women was similar to the full study cohort, the prevalence of HSIL (9.3\%) among HIV-positive women was nearly double the study cohort. A study in South Africa recorded higher prevalence of LSIL (32.5\%) and HSIL (23.3\%) than our study [22] whereas a study in Nigeria showed LSIL and HSIL rates to be $14.3 \%$ and $4.3 \%$, respectively, among HIVpositive women [23].

VIA detected 18 (6.1\%) cases of cervical lesions, which is similar to the $4.7 \%$ reported in Butajira, Ethiopia [24], but lower than the $12.9 \%$ reported in another study in Jimma Town [25] as well as studies in Rwanda and China, where $14.7 \%$ [26] and $11.4 \%$ [12] of women,

Table 3 Predictors of abnormal cervical cytology using LBC, Jimma, 2018

\begin{tabular}{|c|c|c|c|c|c|c|c|c|}
\hline \multirow[t]{3}{*}{ Characteristics } & & \multirow[t]{3}{*}{$N(\%)$} & \multicolumn{2}{|l|}{ LBC Result } & \multirow[t]{3}{*}{ COR(95\%:Cl) } & \multirow{3}{*}{$\begin{array}{l}P- \\
\text { Value }\end{array}$} & \multirow[t]{3}{*}{ AOR(95\%: Cl) } & \multirow{3}{*}{$\begin{array}{l}P \text { - } \\
\text { Value }\end{array}$} \\
\hline & & & $\overline{\text { NILM }}$ & LSIL or HSIL & & & & \\
\hline & & & n (\%) & $n(\%)$ & & & & \\
\hline \multirow[t]{3}{*}{ Parity } & Nulligravida & $34(8.17)$ & $29(85.29)$ & $5(14.71)$ & 1 (ref.) & & 1 & \\
\hline & primigravida & $70(16.83)$ & $55(78.57)$ & $15(21.43)$ & $1.6(0.52-4.8)$ & 0.42 & $1.4(0.43-4.9)$ & 0.56 \\
\hline & Multigravida & $312(75)$ & 219 (70.19) & $93(29.81)$ & $2.5(0.9-6.6)$ & 0.07 & $1.1(0.38-3.3)$ & 0.85 \\
\hline \multirow[t]{5}{*}{ Age } & $21-30$ & 105 (25.06) & 97 (92.38) & $8(7.62)$ & 1 (ref.) & & 1 & \\
\hline & $31-40$ & $179(42.72)$ & $144(80.45)$ & 35 (19.55) & $2.9(1.3-6.6)$ & 0.00 & $2.9(1.3-6.8)$ & 0.00 \\
\hline & $41-50$ & 102 (24.34) & $53(51.96)$ & $49(48.04)$ & $11.2(4.9-25.4)$ & 0.00 & $11.4(4.8-26.9)$ & 0.00 \\
\hline & $51-60$ & $31(7.40)$ & $11(35.48)$ & $20(64.52)$ & $22.0(7.8-61.5)$ & 0.00 & $20.9(7.2-60.9)$ & 0.00 \\
\hline & $>=61$ & $2(0.48)$ & $0(0.00)$ & $2(100.00)$ & 1 & & & \\
\hline \multirow[t]{2}{*}{ Condom Use } & No & 392 (94.23) & 282 (71.94) & $110(28.06)$ & $2.7(0.79-9.3)$ & 0.12 & 1 & \\
\hline & Yes & $24(5.77)$ & $21(87.50)$ & $3(12.50)$ & 1 (ref) & & $1.9(0.52-6.9)$ & 0.33 \\
\hline
\end{tabular}


respectively, had cervical lesions. Among women who were tested using both LBC and VIA in our study, a high proportion $(83.3 \%)$ that tested positive using the LBC test tested negative on the VIA test. This finding is similar to a study in China that showed VIA missed the majority of CIN2+ in older women and was less sensitive than LBC [12]. As our study showed, there was no agreement between LBC and VIA screening tests and variability in the tests was statistically significant (kappa $=0.155, P=0.006$ ).

Organized cytology-based screening is the most efficient screening method for the detection of cervical lesions and has resulted in significant reduction in cervical cancer in developed countries [27]. Financial constraints and technical challenges hinder implementing cytology-based screening in low- and middle-income countries like Ethiopia.

\section{Conclusion}

Given that VIA screening missed most cervical lesions detected by LBC in our study and that a high number of cervical epithelial lesions were detected by LBC, a larger study should be undertaken to determine the diagnostic accuracy of both LBC and VIA against a histological endpoint before adopting either or a combination of the two as screening modalities.

\section{Abbreviations \\ VIA: Visual inspection with 5\% acetic acid; LBC: Liquid-based cytology; HPV: Human papilloma virus; FGAE: Family Guidance Association of Ethiopia; NILM: Negative for intraepithelial lesion or malignancy; LSIL: Low grade squamous intraepithelial lesion; HSIL: High grade squamous intraepithelial lesion; SCJ: Squamous columnar junction; ICL: International Clinical Laboratories; STIs: Sexually transmitted infections}

\section{Acknowledgements}

We would like to thank all the women who participated in the study. We thank Mahlet, Senidu and Addis for their valuable contribution in clinical data collection. We are also grateful for International Clinical Laboratories $(\mathrm{ICL})$, Addis Ababa, Ethiopia for processing the liquid-based cytology results. We acknowledge Ken Divelbess, MPA, provided English edits.

\section{Authors' contributions}

GT, YA, LG, LD, SG, MN, KE, and AA conceptualized and designed the study. GT, YA, MN and KE led the data collection. GT, YA, LG, LD, SG, KE, MN, HH, $\mathrm{MJ}, \mathrm{GG}$ and $\mathrm{AA}$ ccontributed to the data analysis and interpretation of data. GT prepared the first draft of the paper and all authors contributed to the revisions, discussion of results and completion of the final manuscript. All authors have read and approved the manuscript.

\section{Funding}

This study was funded by the Jimma University Research and Postgraduate Coordinating Office. The funder has no role in designing the study, analysis of data and interpretation of the results.

\section{Availability of data and materials}

The datasets used and/or analyzed during the current study are available from the corresponding author on reasonable request.

\section{Ethics approval and consent to participate}

Ethical clearance was obtained from Jimma University's Institutional Review Board (IRB). Written informed consent was obtained from study participants and voluntary participation was maintained throughout the study.
Confidentiality of study participants, including test results was preserved throughout the study.

Consent for publication

"Not applicable".

\section{Competing interests}

The authors have no competing interests to declare.

\section{Author details}

${ }^{1} J i m m a$ University, School of Medical Laboratory Sciences, PO Box $=378$, Jimma, Ethiopia. ${ }^{2}$ Jimma University, Department of Obstetrics \& Gynecology, Jimma, Ethiopia. Jimma University, Department of Epidemiology, Jimma, Ethiopia. International Clinical Laboratories, Addis Ababa, Ethiopia. ${ }^{5}$ Mekelle University, Department of Medical Microbiology and Immunology, Mekelle, Ethiopia. ${ }^{6}$ Department of Microbiology, Makerere University, Kampala, Uganda. ${ }^{7}$ Department of Obstetrics and Gynecology, University of Illinois at Chicago, Chicago, USA.

Received: 13 December 2019 Accepted: 21 July 2020

Published online: 29 July 2020

\section{References}

1. Burchell AN, Winer RL, de Sanjosé S, Franco EL. Epidemiology and transmission dynamics of genital HPV infection. Vaccine. 2006;24:S52-61.

2. Gutiérrez-Xicoténcatl L, Plett-Torres T, Madrid-González CL, Madrid-Marina V. Molecular diagnosis of human papillomavirus in the development of cervical cancer. Salud Publica Mex. 2009;51:s479-s88.

3. Bray F, Ferlay J, Soerjomataram I, Siegel RL, Torre LA, Jemal A. Global cancer statistics 2018: GLOBOCAN estimates of incidence and mortality worldwide for 36 cancers in 185 countries. CA Cancer J Clin. 2018;68(6):394-424.

4. World health orgnaiztion. Human papillomavirus (HPV) and cervical cancer. 2019. Available from: https://www.who.int/en/news-room/fact-sheets/detail/ human-papillomavirus-(hpv)-and-cervical-cancer.

5. Federal Ministry of Health Ethiopia. Disease Prevention and Control Directorate National Cancer Control Plan 2016-2020, 2015.Avaliabel from: https://www.iccp-portal.org/sites/default/files/plans/NCCP\%20Ethiopia\%2 OFinal\%20261015.pdf.

6. Word health organizaton $(\mathrm{WHO})$. International agency for cancr research. GLOBOCAN 2018. https://gco.iarc.fr/today/data/factsheets/populations/231ethiopia-fact-sheets.pdf.

7. Saslow D, Solomon D, Lawson HW, Killackey M, Kulasingam SL, Cain J, et al. American Cancer Society, American Society for Colposcopy and Cervical Pathology, and American Society for Clinical Pathology screening guidelines for the prevention and early detection of cervical cancer. CA Cancer J Clin. 2012;62(3):147-72.

8. Nayar R, Wilbur DC. The Bethesda system for reporting cervical cytology: a historical perspective. Acta Cytol. 2017;61(4-5):359-72.

9. Gibb RK, Martens MG. The impact of liquid-based cytology in decreasing the incidence of cervical cancer. Rev Obste Gynecol. 2011;4(Suppl 1):S2.

10. Gravitt PE, Paul P, Katki HA, Vendantham H, Ramakrishna G, Sudula M, et al. Effectiveness of VIA, pap, and HPV DNA testing in a cervical cancer screening program in a peri-urban community in Andhra Pradesh, India. PLoS One. 2010;5(10):e13711.

11. Almonte M, Ferreccio C, Luciani S, Gonzales M, Delgado JM, Santos C, et al. Visual inspection after acetic acid (VIA) is highly heterogeneous in primary cervical screening in Amazonian Peru. PLoS One. 2015;10(1):e0115355.

12. Li N, Shi J, Franceschi S, Zhang W, Dai M, Liu B, et al. Different cervical cancer screening approaches in a Chinese multicentre study. Bri J Cancer. 2009;100(3):532

13. Syrjänen K, Naud P, Derchain S, Roteli-Martins C, Longatto-Filho A, Tatti S, et al. Comparing PAP smear cytology, aided visual inspection, screening colposcopy, cervicography and HPV testing as optional screening tools in Latin America. Study design and baseline data of the LAMS study. Anticancer Res. 2005;25(5):3469-80.

14. Rani SA, Rama K. Comparative Analysis of Visual Inspection with Acetic Acid And Lugol's lodine And Liquiprep TM in Cervical Cancer Screening with Cervical Biopsy As Gold Standard. IOSR-JDMS. 2016;15(7):54-62.

15. Siebers AG, Klinkhamer PJ, Grefte JM, Massuger LF, Vedder JE, Beijers-Broos A, et al. Comparison of liquid-based cytology with conventional cytology 
for detection of cervical cancer precursors: a randomized controlled trial. JAMA. 2009;302(16):1757-64.

16. Stefanie JK, Klaus JN, Werner H, Armin M, Jochem K, Sibylle S, et al. A randomized trial comparing conventional cytology to liquid-based cytology and computer assistance. Int J Cancer. 2013;132:2849-57.

17. Lowy DR, Schiller JT. Reducing HPV-associated cancer globally. Cancer Prev Res. 2012;5(1):18-23.

18. European guidelines for quality assurance in cervical cancer screening. Luxembourg: Publications Office of the European Union, second edition supplements, 2015.

19. World Health Organotin. Cervical cancer screening and management of cervical pre-cancers. In: Training of health staff in VIA, HPV detection test and cryotherapy. Trainees' handbook; 2007.

20. Sankaranarayanan R, Wesley RS. A practical manual on visual screening for cervical neoplasia: Diamond Pocket Books (P) Ltd; 2003.

21. Erna MK, Minhee K, Michelle SC, Triin U, Catherine G, Reena TA, et al. Immunogenicity and safety of the Quadrivalent human papillomavirus vaccine in HIV-1- infected women. Clin Infect Dis. 2014;59(1):127-35.

22. Michelow P, Sherrin A, Rossouw $L$, et al. Performance of the Cellslide ${ }^{\bullet}$ automated liquid-based cytology system amongst HIV-positive women. Afr J Lab Med. 2016;5(1):a278. http://dx.doi.org/10.4102/ajlm.v5i1.278.

23. Ezechi OC, Pettersson KO, Okolo CA, Ujah IAO, Ostergren PO. The association between HIV infection, antiretroviral therapy and cervical squamous intraepithelial lesions in South Western Nigerian women. PLoS One. 2014;9(5):e97150. https://doi.org/10.1371/journal.pone.0097150.

24. Muluken G, Brhanu T, Friederike R, Tamrat A, Andreas MK, Alemayeh W, et al. Uptake of Cervical Cancer Screening in Ethiopia by Self-Sampling HPV DNA Compared to Visual Inspection with Acetic Acid: A Cluster Randomized Trial. Cancer Prev Res. 2019;12:609-16. https://doi.org/10.1158/ 1940-6207.

25. Zewdie MD, Fessahaye AT, Henok AF. Prevalence and factors associated with VIA positive result among clients screened at family guidance Association of Ethiopia, south west area office, Jimma model clinic, Jimma, Ethiopia 2013: a cross-sectional study. BMC Res Notes. 2015;8:618.

26. Ruzigana G, Bazzet-Matabele L, Rulisa S, Martin AN, Ghebre RG. Cervical cancer screening at a tertiary care center in Rwanda. Gynecologic Oncol Rep. 2017;21:13-6.

27. Herbert A. Cervical Cancer Sreening in England: Liquid Based Cytology in the Context of Moderniztion of the NHS Cevical screening programme. Cent Eur J Public Health. 2008;16:S21-4.

\section{Publisher's Note}

Springer Nature remains neutral with regard to jurisdictional claims in published maps and institutional affiliations.

Ready to submit your research? Choose BMC and benefit from:

- fast, convenient online submission

- thorough peer review by experienced researchers in your field

- rapid publication on acceptance

- support for research data, including large and complex data types

- gold Open Access which fosters wider collaboration and increased citations

- maximum visibility for your research: over $100 \mathrm{M}$ website views per year

At BMC, research is always in progress.

Learn more biomedcentral.com/submissions 